\title{
The flow stress assessment of austenitic-martensitic functionally graded steel under hot compression
}

\author{
H. Salavati ${ }^{a}$, F. Berto ${ }^{b^{*}}$ and Y. Alizadeh ${ }^{a}$
}

${ }^{a}$ Department of Mechanical Engineering, Amirkabir University of Technology, Tehran, Iran ${ }^{b}$ Department of Management and Engineering, University of Padova, Vicenza, Italy

\section{ART ICLE INFO ABSTRACT}

Article history:

Received September 20, 2013

Received in Revised form

October, 14, 2013

Accepted 9 February 2014

Available online

12 February 2014

Keywords:

Hot deformation

Functionally graded steel

Rule of mixture

Zener-Hollomon constitutive

equations

\begin{abstract}
A B T R A C T
In this research, the flow stress of dual layer austenitic-martensitic functionally graded steels (FGSs) under hot deformation loading has been modelled considering the Zener-Hollomon constitutive equations as a function of temperature and strain rate. Functionally graded austenitic-martensitic steels consist of austenite $(\gamma)$ and martensite $(M)$ phases placed on each other in different configurations and produced via Electro Slag Remelting (ESR). The boundary layers properties are obtained by experimental investigation on single phase materials. Finally, the theoretical model is compared with the experimental results measured in the temperature range $1000-1200{ }^{\circ} \mathrm{C}$ and strain rate $0.01-1 \mathrm{~s}^{-1}$ and a good agreement is found.
\end{abstract}

\section{Introduction}

Mechanical behavior of materials under elastic and plastic deformation, creep, fracture, fatigue deserves a great interest in the scientific community and many of researchers work on these topics. Torabi and Aliha (2013) developed a guideline for approving the railway axles made of C35 steel and containing surface and/or in-body defects after manufacturing. First, they modelled several circular cracks on the surface and in the body of the axle at its critical cross-section. Then, they determined the admissible size of such cracks utilizing the fracture mechanics. Finally, they compared the theoretical result for the semi-circular surface crack with the allowable size obtained by the international railway standard .

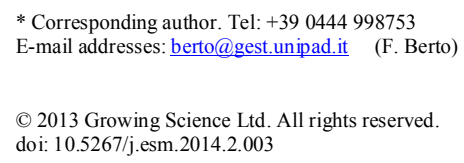


In another work, Torabi (2013) investigated the components weakened by U-notch under different in-plane loading conditions from pure mode I to pure mode II. They presented the brittle fracture curves based on the maximum tangential stress criterion, to evaluate the mixed mode fracture in numerous U-notched samples and also obtained the critical load of the components. Moreover, Torabi (2013) investigated the sudden fracture in V-notched brittle materials under combined tension-shear loading conditions. He used the maximum tangential stress theory for predicting the mixed mode brittle fracture in the specimens weakened by notch. Finally, he compared his results with the experimental ones. Mirlohi and Aliha (2013) investigated the mixed mode I/II crack growth path of an angled crack biaxial plate utilizing the higher-order terms of Williams's series expansion and the maximum tangential stress criterion. They compared their results with the experimentally reported trajectories for the angled crack plate specimen and obtained a very good agreement. Torabi (2013) predicted the critical load of O-notched ductile steel plates under pure tension utilizing the equivalent material concept together with the mean stress and the point stress failure concepts.

The hot deformation behavior of metals and alloys has a great importance for designers of forming processes (hot rolling, forging and extrusion and strong efforts have been made to assess the constitutive equations to describe the flow stress behavior during hot deformation processes (Ma et al., 2009; Shahani et al., 2009; Mandal et al., 2009; Lin et al., 2010; Li et al., 2011). Functionally, graded steels (FGSs) are produced via electro-slag re-melting (ESR) by different arrangement of ferrite $(\alpha)$, austenite $(\gamma)$, bainite $(\beta)$ and martensite $(M)$. In previous studies, FGSs with various configurations have been produced and their tensile behavior has been investigated experimentally (Aghazadeh Mohandesi et al., 2006) and modelled considering Vickers micro-hardness profile of the composite (Nazari et al., 2011). Abolghasemzadeh et al. (2012) proposed a theoretical model to predict the flow stress of $\alpha \beta \gamma$ and $\gamma \mathrm{M} \gamma$ FGSs under hot compression loading based on the rule of mixtures. In that paper, the parameters to be inserted in the constitutive equation of each layer have been determined by using some empirical relationships giving the Vickers hardness profile of the considered structure.

In the present work, Zener-Hollomon constitutive equations were utilized to describe the flow stress of dual layer austenitic-martensitic functionally graded steels under hot deformation loading. Differently from past proposals, the new expression based on Z-H equation is completely analytical and not set considering empirical parameters available from experimental data. The model considers the boundary layers properties obtained by experimental tests on single phase materials. The results of the proposed model have been compared with experimental data measured in the temperature range $1000-1200{ }^{\circ} \mathrm{C}$ and strain rate $0.01-1 \mathrm{~s}^{-1} 1$ and a good agreement is found.

\section{Experimental procedure}

\subsection{Production method of functionally graded steel}

The functionally graded steels were obtained from ingots made of AISI 1020 and austenitic AISI 316L steels utilizing the Electro-Slag Re-melting (ESR) device shown in Fig. 1. The height of initial ferritic and austenitic slices was 26 and $92 \mathrm{~mm}$. The two parts were joined by means of spot welding and were so prepared for the re-melting stage. The re-melting process was carried out under a constant power supply of 16KVA. After re-melting, the composite ingots were forged at $980{ }^{\circ} \mathrm{C}$ and the specimens were air-cooled. By following the procedure described in (Abolghasemzadeh et al. 2012), a martensitic phase was produced during the remelting stage approximately in the middle of the forged specimen. Therefore, dual-layer specimens were produced from the two austenitic graded regions. In order to determine the Vickers hardness corresponding to the boundary edges in the obtained compression specimens, some tests were carried out. The average Vickers hardness of the austenitic and the martensitic edges was found to be 195 and 380 Vickers, respectively. 


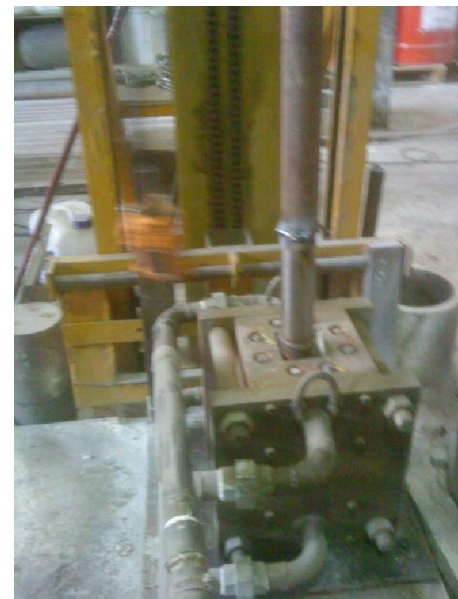

Fig. 1. ESR device used for specimens manufacturing

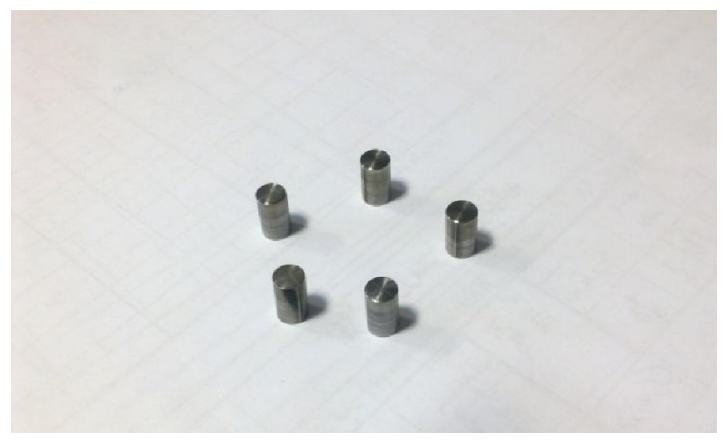

Fig. 2. Hot compression test specimens before testing

\subsection{Test technique}

The flow stress of FGSs was evaluated by means of compression testing. Standard sized specimens were produced following the recommendations provided by ASTM E209. The cylindrical specimens were wire cut to reach a height to diameter ratio equal to 1.5 . In fact, this is the ratio required by the standard in force for compression tests (ASTM E209). The diameter was equal to $6.5 \mathrm{~mm}$ and the height $10 \mathrm{~mm}$ (Fig. 2). The compression load was applied during the tests normally to the interface layers. Moreover, the upper and lower surfaces of the specimens were smoothly polished to reduce the friction during the tests adding also some graphite powder with the aim to improve lubrication (Abolghasemzadeh et al., 2012). The compression tests were carried out in a range of temperature between $1000^{\circ} \mathrm{C}$ to $1200^{\circ} \mathrm{C}$ and three different strain rates $0.01,0.1$ and $1 \mathrm{~s}^{-1}$ by the servo-hydraulic press.

An example of a typical load-displacement curve corresponding to the temperature $1000^{\circ} \mathrm{C}$ and strain rate $0.1 \mathrm{~s}^{-1}$ is shown in Fig. 3. Fifty percent of height reduction was applied to each specimen during each single step of pressure loading (see Fig. 4). The experimental results showed that the flow stress increased by increasing the applied strain rate and decreased by increasing the investigated temperature.



Fig. 3. Stress-strain curve of a test specimen

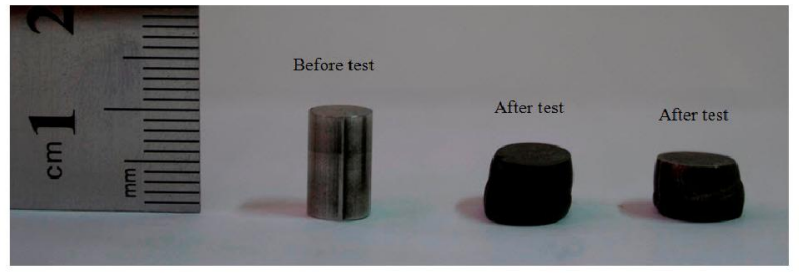

Fig. 4. Hot compression test specimens after testing 


\section{Models}

\subsection{Establishing hot deformation equation}

Among the available constitutive equations for the prediction of the MFS, Z-H parameter (Zener and Hollomon, 1994) allows to take into account the effect of the temperature as well as the strain rate according to the following well known equation:

$$
Z=\dot{\varepsilon} \exp (Q / R T)
$$

In Eq. (1) $\dot{\varepsilon}$ is the strain rate $\left(\mathrm{s}^{-1}\right), Q$ is the deformation process activation energy $\left(\mathrm{J}^{\mathrm{mol}}{ }^{-1}\right), T$ is the temperature $(\mathrm{K})$ and $R$ is gas constant $\left(8.314 \mathrm{Jmol}^{-1} \mathrm{~K}^{-1}\right)$. The term $\exp (Q / R T)$ quantifies the heat of activation, while $Z$ correlates the effect of the temperature with the strain rate.

The followings relationships for $Z$ are available in the literature (Majzoobi et al., 2010; Li et al., 2011; Golmakani \& Kadkhodayan 2011; Abolghasemzadeh et al., 2012):

$$
Z=\left\{\begin{array}{l}
A\left[\sinh \left(\alpha^{\prime}(M F S)\right)\right]^{n}, \\
A^{\prime}(M F S)^{n}, \\
A^{\prime \prime} \exp \left(\beta^{\prime}(M F S)\right)
\end{array}\right.
$$

where $n, A, A^{\prime}, A^{\prime \prime}, \alpha^{\prime}$ and $\beta^{\prime}$ are the material constants and $\alpha^{\prime}=\beta^{\prime} / n$.

A power law is appropriate to describe the stress variation at low stress levels $\left(\alpha^{\prime}(M F S)<0.8\right)$, while an exponential function is usually adopted at high stress loading $\left(\alpha^{\prime}(M F S)>1.2\right)$. The hyperbolic sine function proposed by Sellars and McTegart (1966) is usually used in hot deformation characterized by high strain rates. This function also may be used for creep at low strain rate.

Dealing the present investigation with hot deformation and high strain rates, the hyperbolic sine function was chosen to express $\mathrm{Z}$ :

$$
Z=\dot{\varepsilon} \exp (Q / R T)=A\left[\sinh \left(\alpha^{\prime}(M F S)\right)\right]^{n} \text {. }
$$

A regression analysis of the experimental data leads to determine the material constants by using the following expression:

$$
\ln \dot{\varepsilon}=\left(\ln A-\frac{Q}{R T}\right)+n \ln \sinh \left(\alpha^{\prime}(M F S)\right)
$$

Linear regression applied to experimental data allows evaluating parameters $\alpha^{\prime}$ and $\mathrm{n}$. The activation energy was calculated according to the following equation:

$$
Q=n R\left[\frac{\partial \ln \sinh \left(\alpha^{\prime}(M F S)\right)}{\partial[1 / T]}\right]_{\dot{\varepsilon}}
$$

The slope of the function $\ln \left(\sinh \left(\alpha^{\prime}(M F S)\right)\right)$ when plotted against the inverse of the temperature allowed to evaluate $Q / n R$.

Once the process activation energy was determined the main parameters were substituted in Z-H equation and the diagram $\ln Z$ versus $\ln \left(\sinh \left(\alpha^{\prime}(M F S)\right)\right)$ was plotted. The diagram gave $n$ and $\ln A$ which show also the accuracy of the model.

\subsection{Proposed theoretical model}

The behaviour under hot compression loading was investigated by many researchers (Momeni \& Dehghani, 2011; Lin, 2011). Many of the above mentioned works used the constitutive equations to describe the MFS as a function of temperature and strain rate. The data from the experiments were used to set the main parameters of the model. Since the tests are difficult to be performed and the 
measured parameters sometimes are not accurate, a theoretical model for determination of the MFS of FGSs under hot deformation may be very useful. The composite strain $(\varepsilon)$ can be obtained as follows:

$\varepsilon=\frac{\Delta L_{c o m}}{L}=\sum_{i=1}^{I} \frac{\Delta L_{i}}{L}=\sum_{i=1}^{I}\left(\frac{\Delta L_{i}}{L i} \frac{L i}{L}\right)=\sum_{i=1}^{I} \varepsilon_{i} f_{v i}$

where $f_{v}$ is volume fraction, index $i$ denotes the parameters of $i^{\text {th }}$ layer and $L$ is the initial length of the composite. The axial deformation leads to deformation of each single layer $\left(\Delta L_{i}\right)$ being $\Delta L_{c o m}=\sum \Delta L_{i}$.

By simply differentiating both sides of Eq. (6) leads to the following expression:

$\dot{\varepsilon}=\sum_{i=1}^{I}\left(\dot{\varepsilon}_{i} f_{v i}+\varepsilon_{i} \dot{f}_{v i}\right)$

where subscript ( $\left.{ }^{\circ}\right)$ indicates the variation with time.

In the FGMs considered here the presence of the martensitic layer embedded to the austenitic layers does not permit to neglect the volume fraction variation.

By considering a constant variation of strain and volume for each layer leads to:

$\dot{f}_{v i}=d f_{v i} / d t=\Delta f_{v i} / t, \dot{\varepsilon}_{i}=d \varepsilon_{i} / d t=\varepsilon_{i} / t$ and $\dot{\varepsilon}=\varepsilon / t \mathrm{jh}$

Hence, volume fraction after deformation $\left(f^{\prime}{ }_{v i}\right)$ may be expressed as follows:

$f_{v i}^{\prime}=\frac{L_{i}^{\prime}}{L^{\prime}}=\frac{L_{i}\left(1+\dot{\varepsilon}_{i} t\right)}{L(1+\dot{\varepsilon} t)}=f_{v i} \frac{\left(1+\dot{\varepsilon}_{i} t\right)}{(1+\dot{\varepsilon} t)}$,

where $L^{\prime}$ is the composite length after deformation. From Eq. (8) it follows that:

$\Delta f_{v i}=f_{v i}^{\prime}-f_{v i}=f_{v i} \frac{\left(\dot{\varepsilon}_{i}-\dot{\varepsilon}\right) t}{1+\dot{\varepsilon} t}=f_{v i} \frac{\left(\dot{\varepsilon}_{i}-\dot{\varepsilon}\right) t}{1+\varepsilon}$.

Finally, $\dot{f}_{v i}$ can be expressed as a function of the initial volume fraction of the layer:

$\dot{f}_{v i}=\frac{\Delta f_{v i}}{t}=f_{v i} \frac{\left(\dot{\varepsilon}_{i}-\dot{\varepsilon}\right)}{1+\varepsilon}$.

The steady state strain in the compression test is considered equal to -0.5. Eq. (10) changes accordingly as follows:

$\dot{f}_{v i}=2 f_{v i}\left(\dot{\varepsilon}_{i}-\dot{\varepsilon}\right)$

By substituting Eq. (11) into Eq. (7) it is obtained:

$\dot{\varepsilon}=\sum_{i=1}^{I} f_{v i}\left[\dot{\varepsilon}_{i}+2\left(\dot{\varepsilon}_{i}-\dot{\varepsilon}\right) \varepsilon_{i}\right]$

Eq. (12) can be re-written by explicitly deriving $\dot{\varepsilon}$ in the following form:

$$
\dot{\varepsilon}=\frac{\sum_{i=1}^{I} f_{v i} \dot{\varepsilon}_{i}\left[1+2 \varepsilon_{i}\right]}{\left(1+2 \sum_{i=1}^{I} f_{v i} \varepsilon_{i}\right)} .
$$

In the models of FGMs, the mechanical properties such as elastic modulus are considered to vary exponentially or as power and linear functions together (Samareh Salavati Pour et al., 2103).

The strain $\left(\varepsilon_{i}\right)$ at the $i^{\text {th }}$ layer is obtained by considering Hooke's law in the elastic regime and Hollomon's equation in plastic regime as follows (Aghazadeh Mohandesi \& Shahossinie, 2006).

$\varepsilon_{i}=\varepsilon_{y i}\left(\frac{\sigma_{i}}{\sigma_{y i}}\right)^{1 / n_{i}^{\prime}}=\frac{\sigma_{y i}}{E}\left(\frac{\sigma_{i}}{\sigma_{y i}}\right)^{1 / n_{i}^{\prime}}$

where $\sigma, \sigma_{y}, \varepsilon_{y}$ and $n^{\prime}$ are the uniaxial stress, the yield stress, the yield strain and the strain-hardening exponent, respectively and $E$ is Young's modulus that is a constant in the graded region of the FGS. 
The yield stress $\left(\sigma_{y}\right)$ is proportional to Vickers hardness and the strain-hardening power $(n)$ varies exponentially with the layer position (Aghazadeh Mohandesi and Shahossinie, 2006). Further, the parameters of the Z-H equation vary according to the graded behaviour of the composite as a function of the layers' position. The value of the stress coefficient $(\alpha)$ is about 0.01 and its variation can be neglected. In addition, the inverse of the stress-strain exponent in the constitutive equation $(n)$ represents the sensitivity to the strain rate.

Once the parameters of Z-H equation are known for each layer, the strain rate can be expressed as a function of the temperature and of the MFS:

$\dot{\varepsilon}_{i}=A_{i}\left[\sinh \left(\alpha_{i}^{\prime}(M F S)_{i}\right)\right]^{n_{i}} \cdot \exp \left(-Q_{i} / R T i\right)$

Considering iso-stress and iso-thermal layers, Eq. (15) becomes:

$\dot{\varepsilon}_{i}=A_{i}\left[\sinh \left(\alpha_{i}^{\prime}(M F S)\right)\right]^{n_{i}} \cdot \exp \left(-Q_{i} / R T\right)$

By introducing Eqs. (14-16) into Eq. (13), the final expression for austenitic-martensitic $\gamma M$ FGS can be obtained:

$$
\dot{\varepsilon}=\frac{\sum_{i=1}^{n}\left[f_{v i} A_{i}\left[\sinh \left(\alpha_{\gamma}^{\prime}(M F S)\right)\right]^{n_{i}} \cdot \exp \left(-\frac{Q_{i}}{R T}\right) \times\left(1+2\left\langle\frac{\sigma_{y i}}{E}\left(\frac{M F S}{\sigma_{y i}}\right)^{1 / n_{i}^{\prime}}\right\rangle\right)\right]}{1+\frac{2}{E} \sum_{i=1}^{n}\left[f_{v i} \cdot\left\langle\sigma_{y i}\left(\frac{M F S}{\sigma_{y i}}\right)^{1 / n_{i}^{\prime}}\right\rangle\right]} .
$$

In Eq. (16) index $i$ is related to $\gamma-M$ region; $n$ is the number of layers in this region and symbol $\gamma$ indicate austenitic steel.

It is noteworthy that Eq. (17) contains a single unknown parameter for each applied temperature $\left(T_{a p}\right)$ and the strain rate $\dot{\varepsilon}_{a p}=h\left(M F S, T_{a p}\right)$ is only a function of the flow stress. Hence, the MFS of the composite can be directly determined by using the new proposed equation. The model needs the knowledge of the properties of the boundary layers while the properties of the FGS are not necessary.

\section{Results and discussion}

In this study, hot compression test have been carried out on the dual layer austenitic-martensitic FGS specimen. The range of temperature is from $1000^{\circ} \mathrm{C}$ to $1200^{\circ} \mathrm{C}$ while the applied strain rate is set equal to $0.01,0.1$ and $1 \mathrm{~s}^{-1}$. The measured MFS values are shown in Fig. 5.

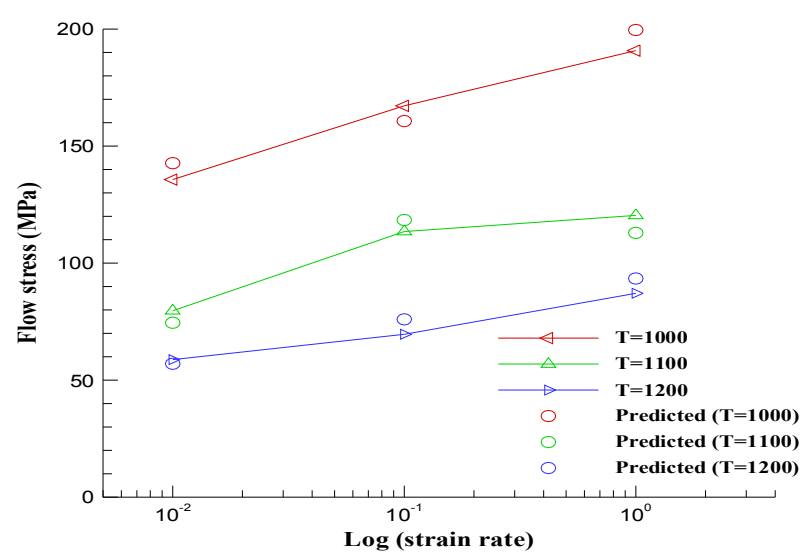

Fig. 5. Variation of flow stress versus strain rate for different temperatures 
The analysis of the present data shows that the MFS decreases by increasing the temperature and this happens at all strain rate values. Furthermore, the MFS decreases by decreasing the strain rate.

\subsection{Application of new model to dual layer austenitic-martensitic FGS}

In order to model the MFS of the dual layer austenitic-martensitic FGS, the height of the specimen is divided into the several homogenous layers. The mechanical properties of the constituent layers in this region change from the initial austenitic steel on one side of the specimen to the martensitic layer on the opposite side. The boundary conditions for the mentioned regions are as follows:

$$
\begin{aligned}
& x=x_{\gamma} \rightarrow n^{\prime}=n_{\gamma}^{\prime}, \alpha^{\prime}=\alpha_{\gamma}^{\prime}, Q=Q_{\gamma}, V H=V H_{\gamma}, \sigma_{y}=\left(\sigma_{y}\right)_{\gamma} \\
& x=x_{M} \rightarrow n^{\prime}=n_{M}^{\prime}, \alpha^{\prime}=\alpha_{M}^{\prime}, Q=Q_{M}, V H=V H_{M}, \sigma_{y}=\left(\sigma_{y}\right)_{M}
\end{aligned}
$$

According to the explanation given in section 3.2, the mechanical properties of each layer in the $\gamma-M$ region have to be determined by imposing the boundary conditions expressed by means of Eq. (18). The mechanical properties are then related to the Vickers micro hardness and the position of each layer as follows:

$$
\begin{aligned}
& n_{i}^{\prime}\left\{\text { or } \operatorname{Ln} A_{i}\right\}=n_{\gamma}^{\prime} \exp \left(\frac{x_{i}-x_{\gamma}}{x_{M}-x_{\gamma}} \ln \frac{n_{M}^{\prime}}{n_{\gamma}^{\prime}}\right) \\
& \sigma_{y i}=(V H)_{i}\left[\frac{\left(\sigma_{y}\right)_{\gamma}}{(V H)_{\gamma}}+\left(\frac{\left(\sigma_{y}\right)_{M}}{(V H)_{M}}-\frac{\left(\sigma_{y}\right)_{\gamma}}{(V H)_{\gamma}}\right) \frac{x_{i}-x_{\gamma}}{x_{M}-x_{\gamma}}\right] \\
& Q_{i}=\frac{\left(Q_{M}-Q_{\gamma}\right)}{\ln \left[\left(\sigma_{y}\right)_{M} /\left(\sigma_{y}\right)_{\gamma}\right]} \ln \sigma_{y i}+\frac{\left[Q_{\gamma} \ln \left(\sigma_{y}\right)_{M}-Q_{M} \ln \left(\sigma_{y}\right)_{\gamma}\right]}{\ln \left[\left(\sigma_{y}\right)_{M} /\left(\sigma_{y}\right)_{\gamma}\right]} \\
& n_{i}=\frac{n_{\gamma} n_{M} \ln \left(\sigma_{y}\right)_{M} /\left(\sigma_{y}\right)_{\gamma}}{\left[\left(n_{M}-n_{\gamma}\right) \ln \sigma_{y i}+\left(n_{M} \ln \left(\sigma_{y}\right)_{M}-n_{\gamma} \ln \left(\sigma_{y}\right)_{\gamma}\right)\right]}
\end{aligned}
$$

In Eqs. (19-22) subscripts $\gamma$ and $M$ indicate the austenitic and martensitic layers.

Parameter $\alpha_{i}{ }_{i}$ for the layers inside the $\gamma-M$ region assumes the same value of the austenitic phase while for the other layer it is equal to that of the austenitic phase. The results from the theoretical model $\left((M F S)_{\text {model }}\right)$ obtained by solving Eq. (17) for various temperatures and strain rates, are shown in Fig. 5. As this figure shows, the predicted MFSs are in good agreement with the experimental values. The average deviation is limited to $10 \%$.

\section{Conclusions}

Hot deformation behaviour of dual layer austenitic-martensitic composites is investigated in the paper and the main findings can be summarised as follows:

- Dual layer austenitic-martensitic FGSs have been made by ESR.

- A theoretical model based on the Zener-Hollomon constitutive equations as a function of temperature and strain rate was developed to predict the flow stress of dual layer austeniticmartensitic FGSs under hot deformation.

- The measured flow stress varies from $58 \mathrm{MPa}$ to $190 \mathrm{MPa}$ for the FGS.

- The average error between the theoretical assessed values and the experimental data was less than $10 \%$ which showed a good agreement. 


\section{References}

Abolghasemzadeh, M., Pour, H., Berto, F., \& Alizadeh, Y. (2012). Modeling of flow stress of bainitic and martensitic functionally graded steels under hot compression. Materials Science and Engineering: A, 534, 329-338.

Aghazadeh Mohandesi, J., \& Shahosseinie, M. H. (2005). Transformation characteristics of functionally graded steels produced by electroslag remelting. Metallurgical and Materials Transactions A, 36(12), 3471-3476.

Aghazadeh Mohandesi, J., Namin, R. P., \& Shahosseinie, M. H. (2006). Tensile behavior of functionally graded steels produced by electroslag remelting. Metallurgical and Materials Transactions A, 37(7), 2125-2132.

Golmakani, M. E., \& Kadkhodayan, M. (2011). Nonlinear bending analysis of annular FGM plates using higher-order shear deformation plate theories. Composite Structures, 93(2), 973-982.

Li, W., Sakai, T., Li, Q., Lu, L. T., \& Wang, P. (2011). Effect of loading type on fatigue properties of high strength bearing steel in very high cycle regime. Materials Science and Engineering: A, 528(15), 5044-5052.

Lin, Y., Li, L. T., \& Xia, Y. C. (2011). A new method to predict the metadynamic recrystallization behavior in 2124 aluminum alloy. Computational Materials Science, 50(7), 2038-2043.

Ma, W., Kou, H., Li, J., Chang, H., \& Zhou, L. (2009). Effect of strain rate on compressive behavior of Ti-based bulk metallic glass at room temperature. Journal of Alloys and Compounds, 472(1), 214-218.

Majzoobi, G. H., Freshteh-Saniee, F., Faraj Zadeh Khosroshahi, S., \& Beik Mohammadloo, H. (2010). Determination of materials parameters under dynamic loading. Part I: Experiments and simulations. Computational Materials Science, 49(2), 192-200.

Mandal, S., Rakesh, V., Sivaprasad, P. V., Venugopal, S., \& Kasiviswanathan, K. V. (2009). Constitutive equations to predict high temperature flow stress in a Ti-modified austenitic stainless steel. Materials Science and Engineering: A, 500(1), 114-121.

Mirlohi, N., Aliha, M.R.M. (2013). Crack growth path prediction for the angled cracked plate using higher order terms of Williams series expansion. Engineering Solid Mechanics, 1, 77-84.

Momeni, A., \& Dehghani, K. (2011). Hot working behavior of 2205 austenite-ferrite duplex stainless steel characterized by constitutive equations and processing maps. Materials Science and Engineering: A, 528(3), 1448-1454.

Nazari, A., Aghazadeh Mohandesi, J., \& Tavareh, S. (2011). Microhardness profile prediction of a graded steel by strain gradient plasticity theory. Computational Materials Science, 50(5), 1781-1784.

Samareh Salavati Pour, H., Berto, F., \& Alizadeh, Y. (2013). A new analytical expression for the relationship between the Charpy impact energy and notch tip position for functionally graded steels. Acta Metallurgica Sinica (English Letters), 26(3), 232-240.

Sellars, C. M., \& McTegart, W. J. (1966). On the mechanism of hot deformation. Acta Metallurgica, 14(9), 1136-1138.

Shahani, A. R., Setayeshi, S., Nodamaie, S. A., Asadi, M. A., \& Rezaie, S. (2009). Prediction of influence parameters on the hot rolling process using finite element method and neural network. Journal of materials processing technology, 209(4), 1920-1935.

Torabi, A.R., Aliha, M.R.M. (2013). Determination of permissible defect size for solid axles loaded under fully-reversed rotating bending. Engineering Solid Mechanics, 1, 27-36.

Torabi, A. R. (2013). Wide range brittle fracture curves for U-notched components based on UMTS model. Engineering Solid Mechanics, 1, 57-68.

Torabi, A. R. (2013). Failure curves for predicting brittle fracture in V-notched structural components loaded under mixed tension/shear: An advanced engineering design package. Engineering Solid Mechanics, 1, 99-118.

Torabi, A. R. (2013). The Equivalent Material Concept: Application to failure of O-notches. Engineering Solid Mechanics, 1, 129-140.

Zener, C., \& Hollomon, J. H. (2004). Effect of strain rate upon plastic flow of steel. Journal of Applied Physics, 15(1), 22-32. 